\title{
Plaats en rol van de klinische chemie in de moderne geneeskunde
}

Citation for published version (APA):

Brombacher, P. J. (1982). Plaats en rol van de klinische chemie in de moderne geneeskunde. Maastricht University. https://doi.org/10.26481/spe.19820423pb

Document status and date:

Published: 23/04/1982

DOI:

$10.26481 / \mathrm{spe} .19820423 \mathrm{pb}$

Document Version:

Publisher's PDF, also known as Version of record

\section{Please check the document version of this publication:}

- A submitted manuscript is the version of the article upon submission and before peer-review. There can be important differences between the submitted version and the official published version of record.

People interested in the research are advised to contact the author for the final version of the publication, or visit the DOI to the publisher's website.

- The final author version and the galley proof are versions of the publication after peer review.

- The final published version features the final layout of the paper including the volume, issue and page numbers.

Link to publication

\footnotetext{
General rights rights.

- You may freely distribute the URL identifying the publication in the public portal. please follow below link for the End User Agreement:

www.umlib.nl/taverne-license

Take down policy

If you believe that this document breaches copyright please contact us at:

repository@maastrichtuniversity.nl

providing details and we will investigate your claim.
}

Copyright and moral rights for the publications made accessible in the public portal are retained by the authors and/or other copyright owners and it is a condition of accessing publications that users recognise and abide by the legal requirements associated with these

- Users may download and print one copy of any publication from the public portal for the purpose of private study or research.

- You may not further distribute the material or use it for any profit-making activity or commercial gain

If the publication is distributed under the terms of Article $25 \mathrm{fa}$ of the Dutch Copyright Act, indicated by the "Taverne" license above, 
Plaats en rol van de klinische chemie in de moderne geneeskunde

\section{REDE}

Uitgesproken bij de aanvaarding van het ambt van hoogleraar in de klinische chemie aan de Rijksuniversiteit Limburg

op vrijdag 23 april 1982

Dr. P.J. Brombacher 

Dames en Heren Leden van het Universiteitsbestuur,

Dames en Heren Leden van de Universiteitsraad,

Dames en Heren Hoogleraren, Docenten en Leden van de Wetenschappelijke Staf,

Dames en Heren Siudenten en voorts Gij allen, die door Uw aanwezigheid blijk geeft van Uw belangstelling,

\section{Zeer gewaardeerde toehoorders,}

Wanneer wij hedenmiddag enkele ogenblikken stil staan bij de rol die de klinische scheikunde speelt in de moderne geneeskunde is het goed een blik terug te werpen op waar deze activiteit begon. Zover als de menselijke geschiedenis te overzien is zijn mensen gefascineerd geweest door de veranderingen die optreden bij wisselende toestanden van gezondheid en ziekte. Dat daarbij magische voorstellingen aanvankelijk de hoofdrol hebben gespeeld is $U$ allen bekend. Dat daarbij ook de klinische chemie een rol heeft gespeeld blijkt uit het volgende voorbeeld:

Wanneer in het oude Egypte een beginnende graviditeit diende vastgesteld te worden werd de urine van de betrokken vrouw aan de priester ter hand gesteld die deze dan sprenkelde op een mengsel van aarde en gerst. Als controle werd zo'n mengsel besprenkeld met urine van de priester zelf. Wanneer nu bleek dat de gerst, bevochtigd met de urine van de vrouw, sneller ontkiemde dan het controle-monster, werd tot zwangerschap geconcludeerd.

Ook naar huidige inzichten is deze proefopzet volstrekt wetenschappelijk te noemen. $\mathrm{Er}$ is een duidelijke probleemstelling, er is een empirisch getoetste hypothese en er is een reproduceerbaar experiment met een zogenaamde blanco-controle. Hetzelfde onderzoek is nog steeds uitvoerbaar, al is de er aan de ten grond liggende hypothese in de loop der tijden gewijzigd. In de oudheid ging men er van uit dat de levenskracht in de urine van de zwangere boven de norm zou zijn gestegen, terwijl men thans de verklaring zoekt in de 
groeistimulerende eigenschappen van in de urine aanwezige hormonen.

Met dit simpele verhaal is de klinische chemie reeds duidelijk aangeduid als het verrichten van onderzoek naar veranderingen in de samenstelling van lichaamsvochten en weefsels, welke het gevolg zijn van gewijzigde physiologische en pathophysiologische toestanden. Dat genoemde veranderingen veelal van chemische aard zijn of, modemer gezegd, zich op moleculair-biologisch niveau afspelen, verklaart dat het onderzoek in zeer ruime mate gebruik maakt van in de chemie ontwikkelde technieken en methoden.

Hoewel nu de indruk gewekt mocht zijn dat reeds eeuwen lang de klinische chemie actief beoefend wordt, is dit toch niet juist. Veelmeer moet gesproken worden van een jonge wetenschap, waarvan een der eerste handboeken pas in 1931 is verschenen. Opvallend is dat het eerste deel van dit werk van Peters en Van Slyke getiteld is "Interpretations" en dat pas in het tweede deel de "Methods"' aan bod komen. Het is in die tijd, circa vijftig jaar geleden, dat in toenemende mate belangstelling ontstond voor de mogelijkheden van de chemie bij diagnostiek en behandeling van ziekten.

Een stormachtige ontwikkeling heeft plaatsgevonden in de laatste dertig jaar. Zoals overal in de exacte wetenschappen is ook in de chemie op vele terreinen het inzicht in de processen, betrokken bij wezenlijke veranderingen van de materie, gegroeid. Ook zijn de technische mogelijkheden, mede onder invloed van de micro-electronica, op verbijsterende wijze toegenomen. Het besef, dat de fundamentele processen in de physiologie steeds meer te herleiden zijn tot en verklaard kunnen worden met georganiseerde stelsels van chemische reacties, heeft steeds meer veld gewonnen. Men spreekt van moleculaire biologie, waaronder wordt verstaan het beschrijven van de essentiële moleculaire interrelaties en reacties die kenmerkend zijn voor gedefiniëerde biologische phenomena en daaraan ten grondslag liggen. Veel wat bekend was wordt nu pas duidelijker. 
Als voorbeeld noem ik $U$ de haematologische diagnostiek, waar de karakterisering van cellen op basis van morphologische kenmerken wordt aangevuld en verdiept door registratie van chemische, enzymcytologische kenmerken. De opmars van de chemie is hier analytisch descriptief en constructief verhelderend.

Het zou niet juist zijn om naast het vele positieve niet ook aandacht te hebben voor de soms oneigenlijke ontwikkelingen in de klinisch-chemische laboratoria. In de jaren dat het noodzakelijk was om analyse-series te mechaniseren en te automatiseren vanwege de onmogelijkheid om het benodigde personeel aan te trekken, heeft de ontwikkeling van de geautomatiseerde apparatuur een grote vlucht genomen, zulks tot zegen van de volksgezondheid. Ontsporingen echter zijn achteraf gezien niet uitgebleven: het ontwikkelen van apparatuur om steeds meer analyses uit eenzelfde bloedmonster simultaan te verrichten heeft er toe geleid dat het gericht doen van onderzoek op basis van overwegingen van pathophysiologische en pathobiochemische aard soms op de achtergrond is geraakt omdat de apparatuur toch eenmaal alle mogelijke analyses verrichtte. Deze onkritische instelling leidt er toe dat uit de veelheid van resultaten, ook van niet gevraagde en zelfs niet bij enige overweging betrokken onderzoekingen, een keuze gremaakt moet worden. De klinicus wordt overstelpt met een palet moleculair biologische gegevens, waarmee hij als ieder zinnig mens verlegen is. Het argument, dat op deze wijze in ieder geval de gegevens, behorende bij niet vermoede pathologische toestanden, gepresenteerd zullen worden, wordt ontkracht wanneer men bedenkt hoeveel schijnbaar pathologische gegevens worden verkregen bij ongericht onderzoek van een gezonde populatie.

Uitgaan van de gangbare methode om het referentiewaardengebied vast te stellen als $95 \%$ van de gezonde populatie betekent dat $5 \%$ van de gegevens buiten dit gebied vallen en niet pathognomonisch zijn of als pathologisch mogen worden aangemerkt. Statistisch onderzoek heeft geleerd dat de kans om 
op een dwaalspoor te komen bij een ziekenhuisbevolking zelfs beduidend groter is dan op een op twintig en wel kan oplopen tot een op zes. Het is dan ook beslist noodzakelijk na te gaan welke onderzoekingen inderdaad nodig en geindiceerd zijn teneinde niet als behandelend klinicus aan grote verwarring ten prooi te raken en als behandeld patiënt het voorwerp te worden van zeer veel, soms zeer belastend en vrijwel altijd kostbaar vervolgonderzoek dat in feite achterwege had kunnen blijven. In dit verband verdient het zeker aanbeveling om te komen tot profielen van gericht laboratoriumonderzoek, uitgaande van een op goede anamnese en physisch onderzoek gebaseerde waarschijnlijkheidsdiagnose.

Van groot belang is het, in het licht van het voorgaande, om de mogelijkheden van het klinisch chemisch laboratorium optimaal te gebruiken. Dit betekent zonder meer dat niet slechts de benadering van pathophysiologische processen en de daarbij behorende moleculair-biologische veranderingen plaats vindt vanuit de klachten van de patiënt en de bevindingen van de onderzoekende arts, maar dat tevens de benodigde onderzoekingen worden bepaald aan de hand van de bij de vermoede diagnose behorende biochemische en pathobiochemische basis. Als voorbeeld noem ik $\mathrm{U}$ de klinisch gestelde diagnose diabetes mellitus bij een patiënt met een coma diabeticum in wiens bloed een te hoog suikergehalte wordt gevonden. In de laatste decennia is gebleken dat voor het bestrijden van de comateuze toestand niet slechts aandacht aan de suikerstofwisseling moet worden besteed maar dat correctie van de te lage $\mathrm{pH}$ van het bloed een eerste vereiste is aangezien immers met name de acidose en niet de hyperglycaemie het levensbedreigend moment stelt. Dat deze acidose het gevolg is van een toegenomen beta-oxidatie van hogere vetzuren is een biochemische vondst die in de kliniek zijn waarde heeft bewezen. Het onvoldoende onderwijzen van biochemische principes aan aanstaande medici dient dan ook als een omissie te worden beschouwd. Zij zijn het immers die straks als behandelend klinicus met de klinisch chemicus 
overleg dienen te voeren over het te verrichten onderzoek en over de betekenis van de daarbij verkregen gegevens.

Evenzeer is het witeraard noodzakelijk dat klinisch chemici die het onderzoek verrichten geschoold worden in de principes van pathophysiologie en geneeskunde. Zeer terecht wordt dan ook in de vierjarige postdoctorale opleiding van klinisch chemici aan deze zaken ruim aandacht besteed. Onbegrijpelijk is het dat het mogelijk is dat als hoofd van een ziekenhuislaboratorium chemici worden benoemd, die de specialisatie in de klinische chemie niet hebben gevolgd. Wellicht dat deze lapsus bij de concretisering van de Wet op de Beroepsuitoefening in de Individuele Gezondheidszorg weggenomen kan worden. Een regeling als geldt voor de ziekenhuisapotheken dient mutatis mutandis te worden ingevoerd voor de klinisch-chemische laboratoria, inhoudende dat elk. ziekenhuis aan het hoofd van het klinisch-chemisch laboratorium een gespecialiseerd en als zodanig geregistreerd klinisch chemicus dient aan te stellen.

Wanneer wij ons dan kritisch opstellen tegenover het onderzoek in het klinisch-chemisch laboratorium gaat onze aandacht uit naar de keuze van de te verrichten analyses en naar de frequentie daarvan, alsmede de daardoor veroorzaakte kosten. Hierover dient regelmatig en bij voorkeur geïnstitutionaliseerd overleg plaats te vinden tussen de aanvragende klinici en de staf van het klinisch-chemisch laboratorium, de klinisch chemici. Nieuwe inzichten op het gebied van bestaande en nieuw gedefinieerde, nader gedetailleerde ziektebeelden, kunnen dan worden getoetst aan de pathobiochemische achtergrond en aan de technische mogelijkheden van het laboratorium. Prioriteiten kunnen worden gesteld en een verstandig gesprek over de verkregen resultaten zal zeker worden gevoerd. Dat ik dit nu stel betekent uiteraard niet dat zodanige samenwerking momenteel niet zou plaats vinden. In Nederland prijzen wij ons gelukkig als klinisch chemici met de uitermate goede samenwerking met de klinisch werkende 
collegae. Nochtans is het met name ook gezien de verruiming van toelating en werkgeving in E.E.G.-verband noodzakelijk dat deze zaken niet uit het oog worden verloren. De eerder genoemde ontwikkeling van profielen voor de diagnostiek moet in deze als zeer positief worden gekenmerkt. Binnen deze profielen wordt dan uiteraard het aantal verschillende onderzoekingen bij de eerste en volgende bloedmonsters afgesproken. Ik heb het U reeds gezegd, het klakkeloos aanvragen van veel onderzoek leidt niet aanwijsbaar tot betere geneeskunde. Ook hier is zeker het woord van toepassing dat wie kennis vergadert, vergadert smart. Voorts dient bedacht te worden dat het oude adagium "baat het niet dan schaadt het ook niet" hier zeker veranderd moet worden in "baat het niet dan schaadt het zeker". Conclusie dus: men vrage laboratoriumonderzoek aan met mate, gericht en in overleg.

Een ander argument om juist bij dit samenspel van aanvraag van onderzoek, rapportage van de resultaten, bespreking daarvan en daaruit volgend verder onderzoek hedenmiddag met U stil te staan, is dat in het huidige tijdsgewricht de economie van de gezondheidszorg een niet langer te verwaarlozen factor is. In Nederland wordt jaarlijks voor circa 500 miljoen gulden in de klinische chemie besteed. Het is waar dat door het mechaniseren en automatiseren van series onderzoekingen de kosten per onderzoek soms lager worden, maar evenzeer is het waar dat het verrichten van te veel onderzoek als gevolg van automatisering de kosten zeer sterk opdrijft, waar geen rendement tegenover staat.

Tevens dient bedacht te worden dat het niet alleen de chemicaliën en arbeidskosten zijn maar dat ook de inrichting van behoorlijke klinisch-chemische laboratoria, een noodzaak voor het uitvoeren van modern geneeskundig onderzoek en behandeling, een kostbare zaak is geworden. Wanneer aan de onderzoeksaspecten geen grens wordt gesteld zal circa iedere vijf jaar de laboratoriumproductie geheel of bijna verdubbelen. Het nationale budget zou dan over enkele decennia nog juist toereikend zijn om het klinisch-chemisch laboratorium- 
onderzoek te betalen terwijl voor andere zaken in het geheel geen geld meer beschikbaar zou zijn. Hoewel er wellicht minder zinnige zaken in de gezondheidszorg zijn die meer geld vragen dan laboratoriumonderzoek, is het toch niet juist de kosten van het laatste en bagatelle te beschouwen. Voorzichtigheid en waakzaamheid is geboden.

Te bedenken valt ook dat bij overautomatisering van het klinisch-chemisch laboratorium soms uit het oog wordt verloren dat de vooruitgang van de diagnostiek en de behandelingscontrole veelal tot stand komt door ontwikkelingswerk aan het front van de moderne geneeskunde. Dit ontwikkelingswerk nu is nog grotendeels mensenwerk of wel handwerk in de nobele zin van het woord.

Wanneer teveel laboratoriumwerk uit de ambachtelijke sfeer wordt gehaald is het vrijwel niet meer mogelijk een goed kader te kweken voor het uitvoeren van geavanceerd onderzoek zonder hetwelk de klinische chemie niet vooruit kan komen. Het soms gehoorde argument dat zulk onderzoek uitsluitend in academische (biochemische) basislaboratoria moet plaats vinden is volstrekt onzinnig: slechts in nauwe samenhang tussen kliniek en klinisch-chemisch laboratorium kan goede klinische chemie worden bedreven. Evenzeer is nauwe samenwerking van het klinisch-chemisch laboratorium met de basale biochemie en analytische chemie noodzakelijk. De klinische chemie immers is de trait d'union tussen chemische basiswetenschappen en klinische pathologie. Dit betekent bijvoorbeeld ook dat in kleinere ziekenhuizen een klinisch-chemisch laboratorium aanwezig moet zijn met een zeer behoorlijk pakket basisverrichtingen, en dat in zo'n kleiner ziekenhuis ook een gespecialiseerd klinisch chemicus als hoofd van het laboratorium aanwezig moet zijn ter bewaking van de kwaliteit van het onderzoek en ten einde het rendement van het verrichtte onderzoek naar de kliniek toe zo hoog mogelijk te maken. De onze hulp vragende patiënten hebben hier recht op, en ze betalen er voor. 
Laat ons tenslotte nog even stil staan bij de criteria die een rol moeten spelen bij de samenstelling van de eerder genoemde diagnostische onderzoeksprofielen. In de literatuur komt men steeds vaker deze zinnige overwegingen tegen. Waar tot voor kort soms te weinig het verwerpen van inmiddels als minder doeltreffend aangemerkt onderzoek voorkwam, krijgt dit nu onder de druk van de economische omstandigheden alle aandacht. Hierin schuilt uiteraard het grote gevaar dat de betalende instanties wellicht te gauw zouden besluiten tot het niet doeltreffend zijn van bepaalde onderzoekingen. Het is dan ook de taak van de beroepsgenoten, klinici en niet-klinici, om op dit terrein terdege werkzaam te zijn. Wanneer wij dan een bepaalde test kiezen om een vermoede diagnose te bevestigen of te verwerpen dan is een eerste eis dat de test specifiek is, dat wil zeggen dat bij afwezigheid van de ziekte het onderzoek negatief uitvalt.

Het is niet altijd gemakkelijk om zo'n test te vinden. Bovendien is een sterk complicerende factor dat vaak niet van een positief/negatief situatie sprake is maar dat het graduele verschillen betreft. Een bepaalde enzymactiviteit in een bloedmonster kan in sommige gevallen zowel op een leveraandoening wijzen als well voorkomen bij een patiënt die zo'n aandoening niet heeft. Er is dan sprake van overlapping van het referentiewaardengebied, de waarden die bij gezonden worden gevonden, en het pathologisch gebied, de waarden die in de bloedmonsters van zieke patiënten worden gevonden. De specificiteit van een test zal dan ook des te beter zijn naarmate referentiewaardengebied en pathologisch gebied verder uiteen liggen.

Een ander criterium is de zogenaamde sensitiviteit van een onderzoek. Het is immers niet voldoende dat een bepaald onderzoek negatief wordt gevonden bij gezonden, men dient ook te verlangen dat het onderzoek bij alle patiënten en niet slechts bij een deel van hen positief uitvalt. De sensitiviteit wordt dan ook gedefinieerd als het positief zijn van de test in monsters afkomstig van personen die de gezochte ziekte hebben. De sensitiviteit is dan beter naarmate het aantal missers 
in deze groep kleiner is.

De beide hier genoemde kriteria, specificiteit ofwel negatief zijn van de test bij gezonden, en sensitiviteit, het positief zijn van de test bij monsters afkomstig van zieken, stellen ons regelmatig voor een dilemma bij de keuze van het te verrichten onderzoek. Immers, wanneer gestreefd wordt naar een zo hoog mogelijke specificiteit, het volstrekt uitsluiten van een vals positief resultaat, dan zall de opzet van het onderzoek zodanig moeten zijn dat alle grensgebieden tot het negatieve gebied worden gerekend. Hierdoor echter wordt de kans groter dat aan de sensitiviteit van de test tekort wordt gedaan. Het vinden van het juiste midden is soms geen eenvoudige zaak. De consequenties van een foutieve uitslag dienen hierbij in overweging te worden genomen. Men dient zich te realiseren of het ten onrechte vinden van een positief test-resultaat en het daarmee ten onrechte de verdenking van ziekte aan een patiënt toebedelen ernstige consequenties heeft dan wel niet van zeer ingrijpende aard is. Anderzijds dient overwogen te worden welke gevolgen het missen van een diagnose kan hebben bij een patiënt met de betreffende ziekte. Een en ander is uiteraard sterk afhankelijk van het ziektebeeld dat wordt bestudeerd. Het ten onrechte iemand verdenken van een lichte bloedarmoede dan wel het niet bij eerste onderzoek een zodanige aandoening op het spoor komen heeft in de regel op korte termijn geen ernstige consequenties. Het ten onrechte niet vinden van een aangeboren stofwisselingsziekte als congenitale hypothyreoïdie daarentegen heeft voor de betrokkene zeer ernstige consequenties die hem tot het einde zijner dagen zullen achtervolgen. In dat geval zal men dus streven naar een zo groot mogelijke sensitiviteit, te meer omdat de verdenking van congenitale hypothyreoïdie bij neonaten die deze. aandoening naderhand niet blijken te hebben, niet primair hoeft te leiden tot ernstige ingrijpende maatregelen.

Een daarbij komende complicerende factor is de mate waarin de betreffende ziekte in de bevolking voorkomt. Een geringe incidentie van de ziekte verlaagt uiteraard de trefkans bij het uitvoeren van diagnostisch onderzoek en verhoogt de kans op 
vals positicve resultaten.

Al deze zaken kunnen mathematisch worden verwerkt en leiden dan tot wat tegenwoordig genoemd wordt de voorspellende waarde van een onderzoek.

Mits met verstand gehanteerd kunnen met behulp van deze gegevens belangrijke beslissingen waarvan de directe invloed op diagnostiek en therapie aanwijsbaar is en die bepaald niet zonder financieel economische consequenties zijn, worden genomen. Men denke slechts aan het verrichten van bevolkingsonderzoek ter opsporing van diverse al dan niet maligne aandoeningen; hiermee is zeer veel werk gemoeid terwijl de resultaten vaak pas na jarenlang onderzoek meetbaar zijn.

Het zij nogmaals gezegd: verstandig gebruik van mathematisch berekende voorspellende waarden van zodanig onderzoek kan bij de beslissing tot het al dan niet uitvoeren daarvan van grote steun zijn.

Dames en heren studenten in de geneeskunde aan deze Faculteit.

Het is met name om Uw belangstelling te wekken voor de klinische chemie dat ik vanmiddag deze zaken te berde heb gebracht. Het onderwijssysteem aan onze Universiteit laat minder dan wellicht wenselijk is de mogelijkheid tot directe overdracht van kennis. Ik kan niet verhelen dat een herhaald verzoek van verschillenden $U$ wer tot nadere instructie mij genoegen doet. Voor $U$ immers is in de eerste plaats deze leerstoel in de klinische chemie ingesteld. Het is bij Uw medische opleiding en Uw medisch handelen in de jaren die komen dat de klinische chemie belangrijke diensten kan verlenen en tot optimalisering van diagnostiek en behandeling kan bijdragen. Ik moge $U$ dan ook aanmoedigen om $U$ met alle vragen die hetzij rechtstreeks, hetzij zijdelings dit vakgebied betreffen, zich tot mij te wenden. Ik beloof $U$ mij naar vermogen in te zetten om $U$ niet alleen in concrete situaties, maar natuurlijk ook dan, van dienst te zijn maar tevens te pogen $U$ te scholen in de denkwijze die in de chemie en ook in de klinische chemie gebruikelijk is en zoveel vrucht heeft afgeworpen. 
Tegen degenen onder $U$ die een afkeer hebben van de natuturwetenschappelijke benadering van de problematiek in de geneeskunde zou ik willen zeggen dat de chemische denkwijze een zeer constructieve is waarbij niet alleen met getallen uit analyses wordt gewerkt maar de integriteit van het probleem steeds weer ter discussie wordt gesteld. Tegen degenen echter die bijzonder gecharmeerd zijn van de analytische werkwijze in de klinische scheikunde zou ik willen zeggen dat nooit uit het oog moet worden verloren dat het geheel meer is dan de som der delen en dat de mens meer is dan zijn bloedchemie.

Aan het einde gekomen van deze inaugurale oratie sluit ik mij gaarne aan bij de traditie om enkele woorden van dank te spreken.

Mijn dank gaat eerst uit naar degenen die mijn scholing in de klinische chemie hebben begeleid. Zeergeleerde Strengers, Uw adviezen en steeds duidelijke aanwijzigingen zijn mij tot grote steun geweest. Gaarne dank ik U hiervoor. Dank ben ik ook verschuldigd aan de collegae en medewerkers van het Weersperplein Ziekenhuis en de afdeling Interne Geneeskunde van de Vrije Universiteit te Amsterdam. De intensieve scholing in de inwendige geneeskunde die ik gedurende een aantal jaren in Uw groep mocht ontvangen is mij nog dagelijks tot steun bij mijn werkzaamheden.

Dank ben ik verschuldigd aan het Bestuur van de Rijksuniversiteit Limburg en de Medische Faculteit voor de medewerking die Uwerzijds verleend is aan mijn benoeming tot hoogleraar in de klinische chemie door Hare Majesteit de Koningin.

Het Bestuur en de Directie van het De Wever-Ziekenhuis in Heerlen bedank ik oprecht voor de mij geboden mogelijkheid deze functie aan onze regionale Universiteit te aanvaarden. De regionalisering van de gezondheidszorg, waarvan wij allen vinden dat het een goede zaak is, wordt door relaties als deze zeker positief beinvloed.

Voorts acht ik het een voorrecht op deze plaats dank te kunnen zeggen aan de collegae, specialisten en huisartsen in 
Heerlen en omstreken, voor de bijzonder prettige en constructieve wijze waarop ik reeds bijna twintig jaar met $U$ kan samenwerken. Ik beloof $U$ mij ook in de toekomst volledig te zullen inzetten om $U$ waar mogelijk van dienst te zijn bij de diagnostiek en de behandelling van Uw patiënten. U kent mijn standpunt dat de klinische chemie slechts kan gedijen als onderdeel van de geneeskunde; ik hoop dit standpunt ook in de komende jaren trouw te blijven.

Niet op de laatste plaats spreek ik gaarne mijn erkentelijkheid uit jegens de collegae klinici en niet-klinici in het Ziekenhuis St. Annadal en de Medische Faculteit van onze Universiteit voor de gastvrijheid waarmee $U$ mij reeds vele jaren hebt ontvangen. De refereeravonden in het Ziekenhuis St. Annadal vormen reeds jaren een plezierig ontmoetingspunt. Ook de hartelijkheid waarmee ik in het Biomedisch Centrum bij de Capaciteitsgroep Biochemie ben ontvangen heeft mij bijzonder goed gedaan.

Ik zou dan willen eindigen met mijn oprechte dank uit te spreken jegens alle medewerkers van het klinisch-chemisch laboratorium van het De Wever-Ziekenhuis voor Uw steeds positieve inzet bij de beoefening van de klinische chemie. Dat mijn werkkring in Heerlen door mij als bijzonder prettig wordt ervaren is wel op de eerste plaats aan $u$ te danken.

Ik heb gezegd. 
